\title{
Introducing In-Class Student Activities in a Community Psychology Course: A Quality Improvement Project
}

\section{Tormod B $\varnothing \mathrm{e}^{1}$}

${ }^{1}$ Department of Psychosocial Science, Faculty of Psychology, University of Bergen

\begin{abstract}
Introduction. Lecturing methods centered around teachers may be less effective teaching tools than approaches utilizing more student-active learning forms. The current quality improvement project investigates implementation of more active learning forms in selected classes in a community psychology course taught at the Faculty of Psychology, University of Bergen. Methods. Oral feedback, and responses from a quality assurance survey from two successive semesters, one prior to the implementation $\left(n_{\mathrm{T} 1}=25,57 \%\right.$ response rate) and one following the implementation $\left(n_{\mathrm{T} 2}=30,83 \%\right.$ response rate) were used to evaluate how students perceived the changes in learning format. Results. Students perceived the lectures to be quite relevant prior to implementation ( $\tilde{\tilde{x}} T_{1}=4$, "To a large extent"), but some students identified a need for more student activities in their feedback. At $T_{2}$, students provided higher relevance ratings to the set of lectures that had been modified $\left(\tilde{\tilde{x}} T_{2}\right.$ $=5$, "To a very large extent"). The difference in relevance ratings from $T_{1}$ to $T_{2}$ was statistically significant $(W=4837, p<.001)$. Within $T_{2}$, the set of modified lectures were also rated as more relevant $(\tilde{\tilde{x}}=5)$ compared to the unmodified lectures $(\tilde{\tilde{x}}=3)$, a difference that was statistically significant $(W=4437, p<.001)$.

Discussion. Student evaluations indicate that the change to more active learning forms was appreciated by the students, as reflected in oral feedback and statistically significantly higher relevance ratings. Personal impressions were somewhat mixed; although it was positive that students were more engaged and active during lectures, and that they rated modified lectures as more relevant, high workloads and constrained time are potential barriers for continued development of teaching methods.
\end{abstract}

Keywords: SoTL; in-class activities; active learning; community psychology Word count: 3000 


\section{Introducing in-class Student Activities in a Community Psychology Course}

"Active learning" aims to transform the learning experience from passive listening or "information-reception" into a more active engagement with the study material. Active learning benefits learning by enabling discussions and explanations among students, facilitating higher order cognitive activities, developing problem solving skills, and is associated with improved skills in writing and critical thinking (Eddy, Brownell, Thummaphan, Lan, \& Wenderoth, 2015; Linton, Pangle, Wyatt, Powell, \& Sherwood, 2014). It has also been argued that active learning approaches allow students to apply "book knowledge" to real-life situations (Brock \& Cameron, 1999). Active learning approaches are also associated with higher engagement, more positive attitudes, and greater motivation towards learning (Chen \& Chiu, 2016; Svinicki, McKeachie, \& McKeachie, 2014). Besides being advantageous to their learning, students actively engaging with each other in class may also benefit them socially and psychologically, and improve student retention (Crosling, Heagney, \& Thomas, 2009; Laal \& Ghodsi, 2012; Swaner, 2007).

Active learning may take many forms (see the website of University of California Berkley \& University of Leicester for some examples), but core elements seem to include students "doing" something, often in collaboration with other students (Bernstein, 2018). Active learning has been a focus in the teaching of psychology for some time (e.g, Daniel, 1974; Gorman, Law, \& Lindegren, 1981), and is still a topic of active research (Jones, 2019; Kingery et al., 2018; Roberts, 2019). Although the participatory elements of certain student-active learning activities have received criticism for representing barriers for some students (Cohen et al., 2019; Eddy et al., 2015), it is still broadly agreed that active learning approaches promote student learning better than more passive approaches (Bernstein, 2018; Prince, 2004; Shellman \& Turan, 2006). It has even been argued that many studies underestimate the potential positive effect of different teaching strategies, due to being under-powered (Tomcho \& Foels, 2009).

\section{Changing the course}

The backdrop for the current quality improvement (QI) project is the introduction of student-active learning components in a course in community psychology taught in the Professional psychology program at the Faculty of Psychology, University of Bergen. The need for revising the course was motivated in parts by student feedback to prior course evaluations, and parts resulting from a change of the person with course responsibility. The revision was also inspired by the author's recent introduction to new skills, tools and knowledge from participating in courses on university pedagogy.

The course consists of three components: lectures, practicum, and a written report, and

The following working paper was submitted in partial fulfillment of the requirements of the "Basismodul $i$ universitetspedagogikk" a part of the pedagogical training and pedagogical qualification of teaching staff at the University of Bergen. I thank May-Britt Sande at the Department of Psychosocial Science, Faculty of Psychology, University of Bergen for designing the survey and making the data available.

Correspondence concerning this article should be addressed to Tormod Bøe, Christiesgate 12, 5015 Bergen.

E-mail: Tormod.Boe@uib.no 
changes were made to a selection of the lectures, see Table 1. Although the lectures already had some components of student-active learning activities built in, more were introduced in the revision. Some examples of the student activities that were introduced or expanded in the course were;

- class discussions, of examples or case-studies provided in or before class,

- think-pair-share activities, in which students worked individually, then in pairs,

- short exercises, on topics such as mapping their own social networks,

- small group discussions, where students solved specific problems or challenges, and

- learning by teaching, students teaching each other from pre-assigned readings.

Students were also given brief problem-based learning tasks (Wiggins, Chiriac, Abbad, Pauli, \& Worrell, 2016) such as identification of local public health challenges, researching evidence based solutions or interventions for these challenges, designing strategies for implementing these interventions, and coming up with methods to evaluate the interventions and their implementation. For most classes, approximately half the time was spent lecturing (e.g., introduction to topic or core problems), and the remaining time was spent on student activities, and on discussing and providing feedback from these activities. The lecturer was present at all time to facilitate discussions when needed, and to answer any questions.

The aim of the following QI-project was to systematically analyse student evaluations obtained before and after implementing more active learning forms in a community psychology course. Data for the analyses are feedback obtained from discussions with the students, and student responses to a formal quality assurance survey administered at course completion.

\section{Methods}

\section{Participants and procedure}

Participants were young adult males and females enrolled in a community psychology course at the University of Bergen. The number of enrolled students were 44 at $T_{1}$ and 36 at $T_{2}$. No further background details of the participants were recorded, but in general, there a more female than male students enrolled in Professional studies in psychology (this is an integrated master/professional degree, qualifying for the degree of canditata/candidatus psychologiae and a psychologist licence).

Oral student feedback is routinely gathered in a 20-30 minute session in class towards the end of the course. For the current report, this information was gathered in late August with approximately 25-30 students attending. Students are asked for positive and negative feedback regarding the course and activities, and also for more general ideas and inputs for improvements of the course. Students who do not wish to provide answers in class are given opportunities to provide written feedback, also anonymously. The lecturer took notes and summarized the responses from the session.

The quality assurance survey is routinely administered after completion of the course, and reports are published in the University Quality Assurance Database. The surveys for the following project was administered to students in March $\left(T_{1}\right)$ and October $\left(T_{2}\right) 2019$. The evaluation forms were completed by 25 participants at $T_{1}$ (57\% response rate) and 30 at $T_{2}$ (83\% response rate). Students were recruited to the survey through postings on 
their learning management system, containing a link to the 20 item survey where students evaluate the course. After the first invitation, two additional reminders were sent out to the students. Using one common link to the survey ensures that the identities of the participants are not disclosed to the lecturer. The project is registered and conducted according to the institutional procedures for QI projects.

\section{Material}

The survey was administered using SurveyXact. From the 20 item survey, the items relevant to the current QI-project were ordinal responses related to perceived relevance of specific lectures to learning outcomes. Lectures given by the author are presented in more detail, see Table 1. All items took the form of the following statement: "To which extent did you perceive the lecture as relevant to the learning outcomes - [insert lecture topic here]", and students responded to the items with the following response options: 1. "To a very little extent", 2. "To a small extent", 3. "To some extent", 4. "To a large extent", 5. "To a very large extent", and 6. "I did not participate in this lecture" (this last response was coded as missing in the analysis).

\section{Data analysis}

The oral feedback was summarized and is presented descriptively. Survey responses from the pre-implementation $\left(T_{1}\right)$ and the post-implementation $\left(T_{2}\right)$ samples are depicted graphically in Figure 1, panels A and B. The data are also presented as density plots to facilitate comparison over the two time points (c.f. panel $\mathrm{C}$ of Figure 1). Changes in mean relevance ratings across items from pre- to post-implementation was analysed with a Wilcoxon/Mann-Whitney test (Mann \& Whitney, 1947) to account for the ordinal nature of the responses from the two independent samples (Liddell \& Kruschke, 2018). In an attempt to adjust for "lecturer-effects", the same statistical test was used to compare the relevance rating in modified lectures $(N=5)$ compared to non-modified lectures $(N=6)$ at $T_{2}$, and compare this same set of lectures also at $T_{1}$, see panel D, Figure 1. Missing data per items were handled with listwise deletion.

$\mathrm{R}$ (Version 3.6.1; R Core Team, 2019) and the R-packages dplyr (Version 0.8.3; Wickham, François, Henry, \& Müller, 2019), ggplot2 (Version 3.2.1; Wickham, 2016), kableExtra (Version 1.1.0.9000; Zhu, 2019), knitr (Version 1.25; Xie, 2015), and papaja (Version 0.1.0.9842; Aust \& Barth, 2018) were used for analyses and to prepare the report.

\section{Results}

\section{Oral feedback from the students}

In their feedback, the students indicated that they appreciated the active learning activities. They did, however, have several suggestions for improving these activities. Specifically they wanted better time to prepare for the activities, more variation in the topics that were discussed in the group-based discussions, and more frequent, but briefer activities. At the same time, some also wanted to go "deeper" into some of the topics of the exercises, implicating that some of the activities should last longer. The students also suggested that panel debates among teachers and staff could be an interesting addition to these activities. 


\section{Responses from the quality assurance survey}

The responses from quality assurance survey administered at $T_{1}$ (prior to implementing student activities) and $T_{2}$ (after the implementation) can be seen in Figure 1. When looking specifically at data from $T_{1}$ (c.f. panel A of Figure 1 and Table 1), it appears that students considered the lectures as largely relevant for the learning outcomes, also prior to the introduction of more student-active methods. Although there were some variation in the responses, both the mean and median responses were centered around a score of four, corresponding to a relevance rating of "To a large extent". At $T_{1}$, there was no statistically significant difference in relevance ratings between the set of lectures that was later modified (i.e. at $\left.T_{2}\right)$ and the other set of lectures $(W=6321.5, p=.21$, c.f. panel $\mathrm{D}$ of Figure 1$)$.

At $T_{2}$, the distribution of responses had shifted towards higher relevance ratings for all modified lectures (see Panels B and $\mathrm{C}$ of Figure 1 and Table 1). The mean relevance ratings were higher for all lectures at $T_{2}$, and the median relevance rating increased from 4 : "To a large extent" to 5: "To a very large extent" for three of the five lectures. Collapsed over all lectures, the change in relevance ratings from $T_{1}(\overline{\bar{x}}=3.97, \tilde{\tilde{x}}=4)$ to $T_{2}(\overline{\bar{x}}=$ 4.44, $\tilde{\tilde{x}}=5)$ was statistically significant $(W=4836.5, p<.001)$. Although the relevance ratings were generally higher at $T_{2}$, a pattern resembling more polarized responses were also noticeable (see Panels B and C of Figure 1). For the two lectures "Social inequality and marginalization" and "Social networks, and social support", students either responded favorably (i.e. largely or very largely relevant), or rather unfavorably (i.e. to a small extent relevant). This pattern of responses may indicate that some students opposed the activities related to these two topics, but it may also have to do with the interest in the topic of these lectures.

When investigating each lecture in detail, there was a statistically significant increase in relevance ratings for two of the five lectures (evaluated at $p_{\text {adjusted }}<.05$, see right column of Table 1). At $T_{2}$, there was also a statistically significant difference in relevance ratings between the modified lectures $(\overline{\bar{x}}=4.44, \tilde{\tilde{x}}=5)$ and unmodified lectures $(\overline{\bar{x}}=3.27, \tilde{\tilde{x}}=3$, $W=4436.5, p<.001$, c.f. panel D of Figure 1).

Table 1

Descriptive data from relevance ratings

\begin{tabular}{|c|c|c|c|c|c|c|c|}
\hline & \multicolumn{3}{|c|}{ Time 1} & \multicolumn{3}{|c|}{ Time 2} & \multirow[b]{2}{*}{$\begin{array}{c}p- \\
\text { value }^{1} \\
\end{array}$} \\
\hline & $n$ & Mean & Med & $n$ & Mean & Med & \\
\hline 1. Psychologist in the community & 24 & 4.0 & 4 & 29 & 4.4 & 5 & 0.064 \\
\hline 2. Social inequality and marginalization & 22 & 4.0 & 4 & 27 & 4.7 & 5 & 0.012 \\
\hline 3. Social capital, social networks, and social support & 21 & 3.9 & 4 & 24 & 4.7 & 5 & 0.005 \\
\hline 4. Evaluation of interventions & 20 & 3.7 & 4 & 24 & 4.2 & 4 & 0.062 \\
\hline 5. Writing reports and preparing for practicum & 25 & 4.1 & 4 & 25 & 4.2 & 4 & 0.838 \\
\hline
\end{tabular}

Note. $\quad{ }^{1}$ Result from Wilcoxon rank sum test. To control the false discovery rate, $P$-values were adjusted with the "BH"-method (Benjamini \& Hochberg, 1995; Benjamini \& Yekutieli, 2001). 
A

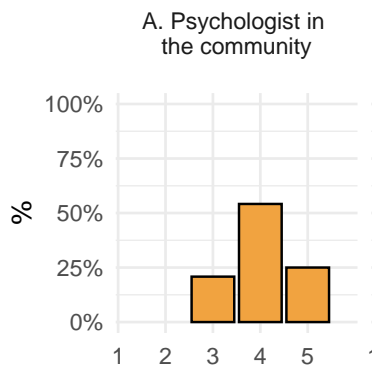

B. Social inequality and marginalization

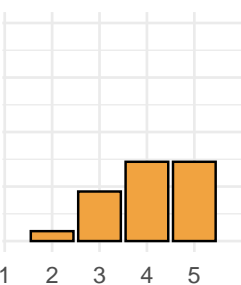

C. Social capital, and social support

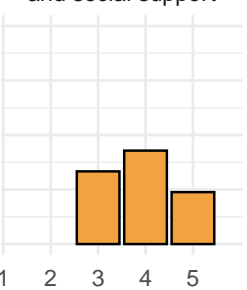
social networks,

D. Evaluating interventions

E. Writing reports and preparing for practicum
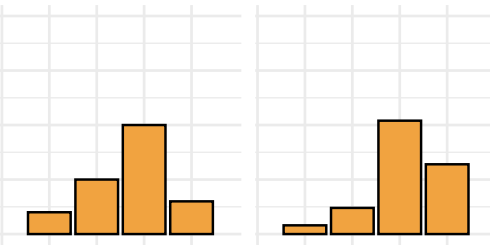

To which extent did you perceive the lecture as relevant to the learning outcomes? (T1)

B

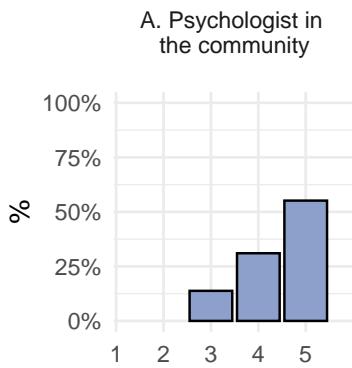

B. Social inequality and marginalization

\section{Social capital, social networks,}

E. Writing reports and preparing for practicum
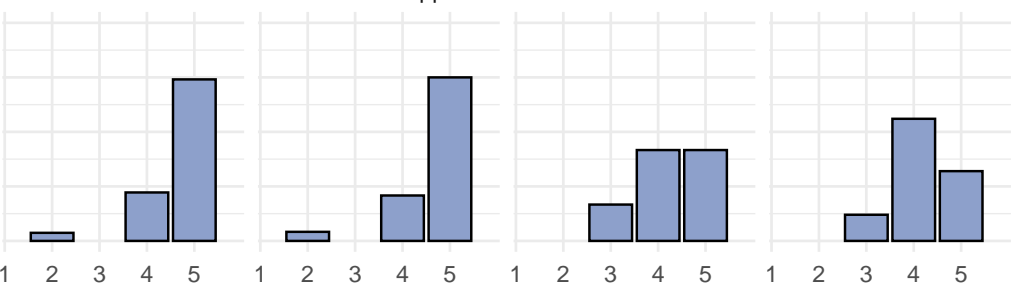
and social support interventions

To which extent did you perceive the lecture as relevant to the learning outcomes? (T2)

C

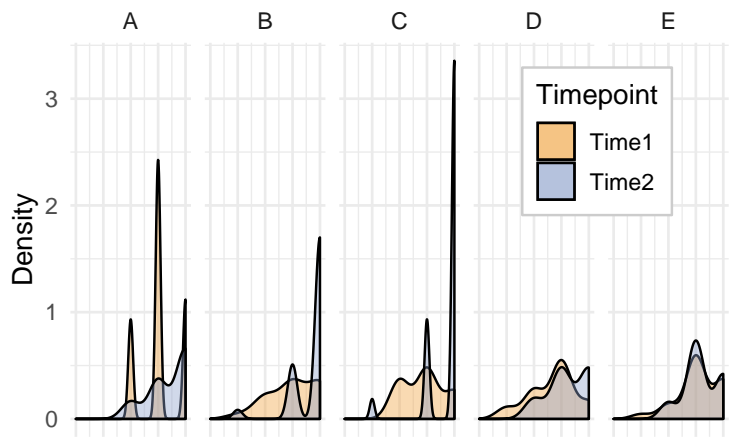

1234512345123451234512345

To which extent did you perceive the lecture as relevant to the learning outcomes? (T1 \& T2)
D

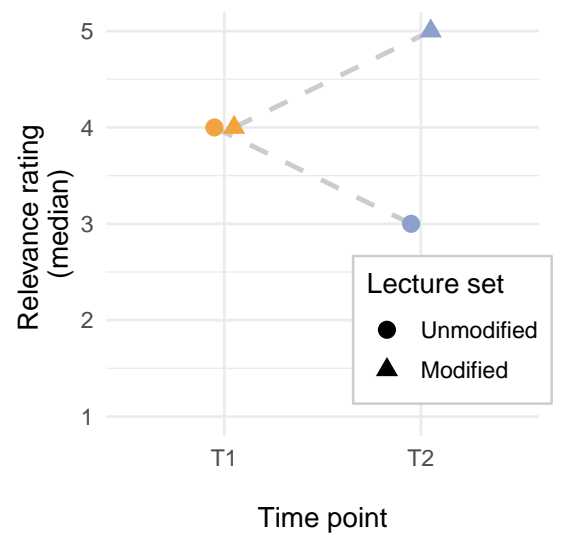

Figure 1. Responses to the quality assurance survey administered to students

Note. Panel $\mathrm{A}$ and $\mathrm{B}$ depicts the survey responses from $T_{1}$ and $T_{2}$, respectively. Panel $\mathrm{C}$ is a density graph comparing the distribution of responses to the two surveys, whereas panel $\mathrm{D}$ illustrates the median relevance ratings at $T_{1}$ and $T_{2}$ for the set of lectures that were modified (Modified) and not (Unmodified). For $x$-axis $(y$-axis in Panel D): 1 = "To a very little extent", 2 = "To a small extent", 3 = "To some extent", 4 = "To a large extent", $5=$ "To a very large extent". The letters in panel $\mathrm{C}$ headings corresponds to lectures: A = "Psychologist in the community", B = "Social inequality and marginalization", C = "Social capital, social networks, and social support", $\mathrm{D}=$ "Evaluating interventions", $\mathrm{E}=$ "Writing reports and preparing for practicum". 


\section{Discussion}

The aim of this QI-project was to evaluate how introduction of more student-active learning components in a course in community psychology was related to student opinions and relevance ratings obtained from oral feedback and survey responses. Students rated lectures at $T_{1}$ as largely relevant, but even more so at $T_{2}$, after expanding the studentactive learning activities. The modified lectures did also obtain higher relevance ratings than the unmodified lectures at $T_{2}$, a pattern not present at $T_{1}$. Other factors such as the lecturer, topics, and the content in general was unmodified, strengthening the hypothesis that introducing student-active learning was related to higher relevance ratings. Oral feedback from the students indicated that they enjoyed the student-active learning approaches, but that there should be greater variation in both content and structure of these activities.

The request for more variation in the student-active components also resonates well with my own experiences and reflections throughout the semester. Whereas some of the student-active teaching tools seemed to work well, I noticed that others were perceived as repetitive and less useful by some students. This suggest that I have to build a bigger repertoire of student-active teaching tools, provide students with more varied activities, and improve how each activity is aligned with the learning outcome(s). Relatedly, the current project identified some apparent tension arising from different students having different needs. This was exemplified by some students wanting more frequent and briefer activities, and others wanting activities allowing them to go "deeper" and spend more time on particular topics. The tendency towards more polarized relevance ratings at $T_{2}$ may also be interpreted in this light. This underscores the obvious fact that "one size does not fit all", and may be an argument for supplying students with a "buffet" of different activities too chose from, all related to the same learning outcome(s). Students learn in different ways, and with more flexible adaptations and individualization of student activities, we may contribute to all learning to their best ability (Biggs, 1999; Eddy et al., 2015).

This need for flexibility and adaptability on behalf of the teacher or academic staff must also been seen in relation to the limited time and resources that is allotted to teaching preparation and course administration. Workloads in academia are high, and related to excessive stress levels among staff, in turn associated with lower job satisfaction and reduced commitment to their organization (Abouserie, 1996; Tytherleigh, Webb, Cooper, \& Ricketts, 2005). Higher quantitative demands on academic staff has also been related to burnout, through more work-family conflicts (Watts \& Robertson, 2011), and to what has been labelled an "epidemic of poor mental health among academic staff" (Morrish, 2019). Increasing demands for "excellence" in both research and teaching should therefore be accompanied with better structural and administrative support. It is also imperative that norms for workloads relating to administrative duties and teaching preparation should take into account the actual working patterns and resources that these task demands. In agreement with Ministry of Education and Research (2017), I too think that the development of quality education should not be left to individual academics with an enthusiasm for pedagogy, but

seen as a shared responsibility between management and the academic community-I would also add-and reflected in resource allocation.

Still, I have also experienced that providing students with tools to take greater 
responsibility for their learning sometimes may create more space (Baepler, Walker, \& Driessen, 2014). I no longer have the obligation to "fill time with content", but may rather be present to give feedback and facilitate activities among the students. Participating in student discussions have been energizing, in contrast to the feelings of drainage sometimes associated with lecturing for several hours. Spending time to develop good learning activities may also save time in the longer run. Teachers may accumulate a repertoire of effective activities and techniques that may be implemented-with small modifications-into different courses and reused for other topics. Also, devising general principles of making studentactivities, like "how to recast topic $X$ or $Y$ into a class discussion" or "which kinds of articles are suited for learning by teaching activities" would be examples of knowledge that could be applied more general by the teacher, and thereby increase motivation for spending the time to make student activities.

The overarching goal of the current course is to prepare students for becoming competent community psychologists. To reach this goal, there is further room for improving the alignment of teaching materials and settings, and the assessment and examination procedures (Biggs, 1999; Meij \& Merx, 2018). Specifically, further developments and revisions of the course should provide opportunities for including more formative assessment methods to facilitate the learning process (Dixson \& Worrell, 2016). One idea is to replace the written report with a portfolio assessment, where students submit short written assignments related to problem based learning goals (e.g. for identifying local public health challenges, finding evidence based solutions/interventions, designing strategies for implementation, and strategies to evaluate interventions and their implementation). Feedback and opportunities to revise each of these assignments could substitute the formative assessment, while the summative assessment could be to hand in a final version of this portfolio for grading at course completion. Another, although less developed idea, is to investigate opportunities for including sustainable assessment methods (Heitink, Van der Kleij, Veldkamp, Schildkamp, \& Kippers, 2016; Sala, Ciuffo, \& Nijkamp, 2015). The motivation behind this change would be to better prepare the becoming practicing psychologists for their future learning needs, in a rapidly changing area of work (Meyers, Meyers, \& Grogg, 2017).

\section{Strengths and limitations}

A strength of the current QI-project is the availability of data both prior to and after the introduction of student-active learning activities. This data allows personal reflections and oral student feedback to be complemented with standard questions gathered anonymously in the quality assurance survey. Another strength is that the introduction of student-active learning in itself may be presumed to have had positive impacts on student learning, and potentially also student well-being (Swaner, 2007).

One of the main limitations of the current project is the reliance on student evaluations and opinions for demonstrating effectiveness of the changes implemented in the course. It has been argued that student opinions and evaluations are both "wildly used [...] and woefully inadequate" as measures of student learning (McCarthy, Niederjohn, \& Bosack, 2011, p. 78). Relatedly, relatively few participants responded to the quality assurance survey at $T_{1}$. This may have biased the responses, making them less reliable to count on for deciding how to further develop the course. Interestingly, the response rate to the survey increased by $25 \%$ 
at $T_{2}$. Further studies should evaluate to which extent this could be indicative of higher engagement by the students, related to introduction of student-active learning.

A second limitation relates to the limited opportunities for making causal claims about the effectiveness of the course changes. Although some of the structural elements surrounding the lectures was kept similar at $T_{1}$ and $T_{2}$, it is difficult to conclude regarding the causal relationship behind the increase in relevance ratings. The validity of the ratings may be biased by factors such as likability (attitudes towards teachers) and prior subject interest (Feistauer \& Richter, 2018). Other unobserved factors may also have confounded the association between student-active learning activities and relevance ratings.

\section{Conclusion}

The qualitative and quantitative feedback from students has been highly informative in deciding when and how to utilize student-active learning activities in the course in community psychology. For me, as a teacher, getting better acquainted with university pedagogy has been inspirational. Although I too struggle with limited time and ample demands, I believe in providing our students with high quality teaching, and that student-active teaching tools play an important role in doing so. I intend to keep gradually introducing more and different tools to enhance learning into my courses, and I will keep revising my teaching methods, better align learning outcomes with assessment methods, and continue to take a research stance towards developing ways to improve student learning. With future developments of the course towards more aligned learning outcomes and assessment, we will also be in a better position to evaluate how changes in teaching approaches is related to actual performance and learning by the students. 


\section{References}

Abouserie, R. (1996). Stress, Coping Strategies and Job Satisfaction in University Academic Staff. Educ. Psychol., 16(1), 49-56. doi:10/bppt4c

Aust, F., \& Barth, M. (2018). papaja: Create APA manuscripts with R Markdown. Retrieved from https://github.com/crsh/papaja

Baepler, P., Walker, J. D., \& Driessen, M. (2014). It's not about seat time: Blending, flipping, and efficiency in active learning classrooms. Computers $\&$ Education, 78, 227-236. doi:10/f6g82d

Benjamini, Y., \& Hochberg, Y. (1995). Controlling the false discovery rate: A practical and powerful approach to multiple testing. J. R. Stat. Soc. Ser. B Methodol., 57(1), 289-300. doi:10/gfpkdx

Bernstein, D. A. (2018). Does active learning work? A good question, but not the right one. Scholarsh. Teach. Learn. Psychol., 4(4), 290-307. doi:10/gf8tbc

Biggs, J. (1999). What the Student Does: Teaching for enhanced learning. High. Educ. Res. Dev., 18(1), 57-75. doi:10/drgphk

Brock, K. L., \& Cameron, B. J. (1999). Enlivening political science courses with Kolb's learning preference model. PS Polit. Sci. Polit., 32(2), 251-256.

Chen, C.-H., \& Chiu, C.-H. (2016). Collaboration Scripts for Enhancing Metacognitive Self-regulation and Mathematics Literacy. Int $J$ of Sci and Math Educ, 14(2), 263-280. doi:10/f8fcbw

Cohen, M., Buzinski, S. G., Armstrong-Carter, E., Clark, J., Buck, B., \& Reuman, L. (2019). Think, pair, freeze: The association between social anxiety and student discomfort in the active learning environment. Scholarsh. Teach. Learn. Psychol. doi:10/gf8q2t

Crosling, G., Heagney, M., \& Thomas, L. (2009). Improving Student Retention in Higher Education: Improving Teaching and Learning. Aust. Univ. Rev., 51(2), 9.

Daniel, R. S. (1974). Teaching of psychology has already had a long past. Teach. Psychol., (1), $32-34$.

Dixson, D. D., \& Worrell, F. C. (2016). Formative and Summative Assessment in the Classroom. Theory Pract., 55(2), 153-159. doi:10/gf5z3q

Eddy, S. L., Brownell, S. E., Thummaphan, P., Lan, M.-C., \& Wenderoth, M. P. (2015). Caution, Student Experience May Vary: Social Identities Impact a Student's Experience in Peer Discussions. LSE, 14(4), ar45. doi:10/gfz382

Feistauer, D., \& Richter, T. (2018). Validity of students' evaluations of teaching: Biasing effects of likability and prior subject interest. Studies in Educational Evaluation, 59, 168-178. doi:10/gfsr26

Gorman, M. E., Law, A., \& Lindegren, T. (1981). Making Students Take a Stand: Active Learning in Introductory Psychology. Teaching of Psychology, 8(3), 164-166. doi:10/dsc7vp

Heitink, M. C., Van der Kleij, F. M., Veldkamp, B. P., Schildkamp, K., \& Kippers, W. B. (2016). A systematic review of prerequisites for implementing assessment for learning in classroom practice. Educational Research Review, 17, 50-62. doi:10/gf5z3k

Jones, J. A. (2019). Scaffolding self-regulated learning through student-generated quizzes. Active Learning in Higher Education, 20(2), 115-126. doi:10/gcsmmw 
Kingery, J. N., Gaskell, M. E., Toner, S. R., Rice, S. E., Gray, M. L., Milligan, J. A., \& Milmoe, M. H. (2018). Active Learning in a Child Psychology Course: Observing Play Behavior at a Children's Museum. Psychology Learning \& Teaching, 17(2), 209-218. doi:10/gf8s99

Laal, M., \& Ghodsi, S. M. (2012). Benefits of collaborative learning. Procedia - Social and Behavioral Sciences, 31, 486-490. doi:10/fxkth2

Liddell, T. M., \& Kruschke, J. K. (2018). Analyzing ordinal data with metric models: What could possibly go wrong? Journal of Experimental Social Psychology, 79, 328-348. doi:10/gfdbv8

Linton, D. L., Pangle, W. M., Wyatt, K. H., Powell, K. N., \& Sherwood, R. E. (2014). Identifying Key Features of Effective Active Learning: The Effects of Writing and Peer Discussion. LSE, 13(3), 469-477. doi:10/gfz4hp

Mann, H. B., \& Whitney, D. R. (1947). On a Test of Whether one of Two Random Variables is Stochastically Larger than the Other. Ann. Math. Statist., 18(1), 50-60. doi:10/fgp7wb

McCarthy, M. A., Niederjohn, D. M., \& Bosack, T. N. (2011). Embedded Assessment: A Measure of Student Learning and Teaching Effectiveness. Teaching of Psychology, 38(2), 78-82. doi:10/gf3zpf

Meij, L. W.-d., \& Merx, S. (2018). Improving curriculum alignment and achieving learning goals by making the curriculum visible. Int. J. Acad. Dev., 23(3), 219-231. doi:10/gf86g3

Meyers, J., Meyers, A. B., \& Grogg, K. (2017, September). Prevention Through Consultation: A Model to Guide Future Developments in the Field of School Psychology. The Future of School Psychology Conference. doi:10.4324/9780203764251-3

Ministry of Education and Research. (2017). Quality Culture in Higher Education (No. (Meld. St. nr 16)). Ministry of Education and Research. Retrieved from https://www.regjeringen.no/contentassets/aee30e4b7d3241d5bd89db69fe38f7ba/en-gb/ pdfs/stm201620170016000engpdfs.pdf

Morrish, L. (2019). Pressure Vessels: The epidemic of poor mental health among higher education staff (No. 20) (p. 76). Higher Education Policy Institute.

Prince, M. (2004). Does Active Learning Work? A Review of the Research. J. Eng. Educ., 93(3), 223-231. doi:10/br39

R Core Team. (2019). R: A language and environment for statistical computing. Vienna, Austria: R Foundation for Statistical Computing. Retrieved from https://www.R-project.org/

Roberts, D. (2019). Higher education lectures: From passive to active learning via imagery? Active Learning in Higher Education, 20(1), 63-77. doi:10/gf8tcb

Sala, S., Ciuffo, B., \& Nijkamp, P. (2015). A systemic framework for sustainability assessment. Ecological Economics, 119, 314-325. doi:10/f7x29s

Shellman, S. M., \& Turan, K. (2006). Do simulations enhance student learning? An empirical evaluation of an IR simulation. J. Polit. Sci. Educ., 2(1), 19-32. doi:10/dfpvx3

Svinicki, M. D., McKeachie, W. J., \& McKeachie, W. J. (2014). McKeachie's teaching tips: Strategies, research, and theory for college and university teachers (Fourteenth edition.). Australia; United States: Wadsworth, Cengage Learning.

Swaner, L. E. (2007). Linking Engaged Learning, Student Mental Health and Well-Being, and Civic Development: A Review of the Literature. Lib. Educ., 93(1), 16-25. Retrieved from https://eric.ed.gov/?id=EJ762291 
Tomcho, T. J., \& Foels, R. (2009). The Power of Teaching Activities: Statistical and Methodological Recommendations. Teaching of Psychology, 36(2), 96-101. doi:10/bf7j78

Tytherleigh, M. Y., Webb, C., Cooper, C. L., \& Ricketts, C. (2005). Occupational stress in UK higher education institutions: A comparative study of all staff categories. High. Educ. Res. Dev., $24(1), 41-61$. doi:10/d742qw

Watts, J., \& Robertson, N. (2011). Burnout in university teaching staff: A systematic literature review. Educ. Res., 53(1), 33-50. doi:10/bkh4nv

Wickham, H. (2016). Ggplot2: Elegant graphics for data analysis. Springer-Verlag New York. Retrieved from https://ggplot2.tidyverse.org

Wickham, H., François, R., Henry, L., \& Müller, K. (2019). Dplyr: A grammar of data manipulation. Retrieved from https://CRAN.R-project.org/package=dplyr

Wiggins, S., Chiriac, E. H., Abbad, G. L., Pauli, R., \& Worrell, M. (2016). Ask not only "What can problem based learning do for psychology?", But "What can psychology do for problem based learning?": A review of the relevance of problem based learning for psychology teaching and research. Psychology Learning \& Teaching, 15(2), 136-154. doi:10/f3r2vf

Xie, Y. (2015). Dynamic documents with $R$ and knitr (2nd ed.). Boca Raton, Florida: Chapman; Hall/CRC. Retrieved from https://yihui.name/knitr/

Zhu, H. (2019). KableExtra: Construct complex table with 'kable' and pipe syntax. 